УДК 547.458.88+664.292

\title{
РЕОЛОГИЧЕСКИЕ СВОЙСТВА КОНЦЕНТРИРОВАННЫХ ВОДНЫХ РАСТВОРОВ ГИДРОЛИЗОВАННЫХ ПРОИЗВОДНЫХ
}

\section{ГАЛАКТОМАННАНА}

\author{
() Д.М. Амонова*, М.Ю. Мухамеджанова, Ш.А. Шомуротов, А.С. Тураев \\ Институт биоорганической химии АН Республики Узбекистан, ул. Мирзо \\ Улугбека, 83, Ташкент, 100125 (Узбекистан), e-mail: dilya87-82@mail.ru
}

\begin{abstract}
Исследован процесс кислотного гидролиза природного полисахарида галактоманнана Gleditsia Aquatica при различных температурах. Установлено, что с повышением температуры процесса снижаются молекулярные массы образцов галактоманнана и изменяются соотношения галактозы и маннозы. Изучены реологические свойства концентрированных водных растворов гидролизованных производных галактоманнана. Показано, что изученные системы являются неньютоновскими жидкостями с псевдопластичным характером аномалии вязкого течения.

Оценена структура водных растворов гидролизованных образцов галактоманнана по величинам среднестатистических размеров кинетических единиц. позволяющим сравнить подвижность структурных элементов и их размеры для концентрированных систем. Показано, что природа и строение макромолекул является основным фактором, определяющим структуру концентрированных растворов систем на основе галактоманнана с различной степенью гидролиза.

Ключевые слова: галактоманнан, гидролиз, реология, эффективная вязкость, напряжение сдвига, энергия активации вязкого течения.
\end{abstract}

\section{Введение}

В настоящее время все большее внимание ученых привлекают исследования природных полисахаридов, направленные на определение взаимосвязи их молекулярной структуры с макроскопическими свойствами. Весьма интересными и перспективными с этих позиций представляются растительные полисахариды - галактоманнаны (ГМ), обладающие высокой и разнообразной физиологической активностью и специфическими физическими свойствами [1-4]. Реологические свойства ГМ, определяемые их высокой гелеобразующей способностью в водных средах, позволили использовать ГМ в пищевой, фармацевтической, медицинской, косметической, текстильной и других отраслях промышленности в качестве загустителей, эмульгаторов, стабилизаторов дисперсных систем, геле- и структурообразователей [5, 6, 8-10]. ГМ внесены в группу биологически активных пищевых добавок [5, 7]. ГМ используются для приготовления капсул, пролонгирующих действие некоторых лекарств в организме, их применяют как матрицы для иммобилизации лекарственных средств [6, 8, 9].

\footnotetext{
Амонова Дилноза Мухторовна - старший научный сотрудник, тел.: (+99871) 262-35-40,

e-mail: dilya87-82@mail.ru

Мухамеджанова Муяссархон Юсупжановна - кандидат химических наук, старший научный сотрудник, тел.: (+99871) 262-35-40,

e-mail: mukhamedjanovam_@mail.ru

Шомуротов Шавкат Абдуганиевич - кандидат химический наук, старший научный сотрудник, тел.: (+99871) 262-35-40, e-mail: shsha@mail.ru Тураев Аббасхан Сабирханович - доктор химических наук; профессор; тел.: (+99871) 262-35-40, e-mail: abbaskhan@mail.ru
}

Модификация макромолекул ГМ методом гидролиза, при котором возможно регулирование молекулярной структуры полисахарида и варьирование соотношения моносахаридов маннозы и галактозы, образующих макромолекулу ГМ в процессе гидролиза, позволит направленно формировать молекулярное строение ГМ, что в конечном итоге создаст возможность получить макромолекулярные матрицы с заданным комплексом свойств. Как известно, ГМ в большинстве случаев находят приме-

\footnotetext{
*Автор, с которым следует вести переписку.
} 
нение в виде водных растворов, поэтому исследование реологических свойств их концентрированных водных систем весьма информативно, поскольку именно реологические свойства наиболее чувствительны к изменениям молекулярной структуры полимерных матриц полисахаридов [11, 12].

Цель настоящего исследования - изучение процесса гидролиза ГМ и исследование реологических свойств концентрированных водных растворов образцов ГМ, гидролизованных при различных температурах, выявление роли строения макромолекул ГМ, молекулярных масс и соотношений маннозы и галактозы на структуру концентрированных растворов при действии внешних сил.

\section{Экспериментальная часть}

Объекты исследования. Исследовался образец галактоманнана Gleditsia Aquatica, полученный по методике [1]. Гидролиз ГМ проводили по методу [1] при варьировании температуры процесса.

Анализ полученных образцов проводили методами элементарного анализа, ИК-спетроскопией. Соотношения галактозы и маннозы образцов ГМ определяли по $[1,13]$.

Молекулярные массы $\mathrm{M}_{\mathrm{w}}$ и молекулярно-массовые распределения определены методом эксклюзионной жидкостной хроматографии (ЭЖХ) на жидкостном хроматографе [14], состоящем из плунжерного насоса Merk-Hitachi L-6000A, рефрактометрического детектора Shodex RI-101, детектора многоуглового рассеяния лазерного света (МРЛС) DAWN NSP, Watt Technology (США), ручного инжектора проб Rheodine 2104, дегазатора элюента и двух термостатированных при $25^{\circ} \mathrm{C}$ хроматографических колонок PL Aquagel-OH Mixed, соединенных последовательно. Длина и внутренний диаметр каждой колонки соответственно составляли 300 и 7,5 мм. Элюентом служил водный раствор $\mathrm{NaCl}$ с концентрацией 0,1 моль/л. Объем вводимой пробы составлял 100 мкл. Объемная скорость подачи элюента составляла 60 мл/час. Растворы полимеров перед вводом в хроматографическую колонку пропускали через фильтр с размером пор 0,22 мкм. Анализ образцов ГМ с помощью МРЛС осуществляли на длине волн 632,8 нм [14].

ИК-спектры сняты на спектрометре Brücker Tensor 27 (длины волны: 400-4000 $\mathrm{cm}^{-1}$, шаг 4/см) методом Diamant-ATR.

Молекулярные массы $\mathrm{M}_{\mathrm{w}}$ синтезированных образцов и их молекулярно-массовое распределение определялись также методом седиментации на приборе МОМ (Венгрия). Характеристические вязкости [ๆ] определялись на вискозиметре Уббелоде при $25^{\circ} \mathrm{C}$ в водном растворе $0,1 \mathrm{H} \mathrm{NaCl}$.

Исследования реологических свойств концентрированных $3 \%$ водных растворов ГМ проводили на ротационном вискозиметре «Реотест-2» с рабочим узлом из коаксиальных цилиндров $[15,16]$ в интервале напряжений $\left(1,6-3 \times 10^{3}\right)$ Па и скоростей сдвига $\left(0,2-1,3 \times 10^{3}\right) \mathrm{c}^{-1}$ при температурах $25,40,55,70^{\circ} \mathrm{C}$.

\section{Обсуждение результатов}

Гидролиз галактоманнана Gleditsia Aquatica

Изучаемый в настоящем исследовании природный полисахарид - галактоманнан Gleditsia Aquatica (рис. 1) по своей сложной комплексной структуре имеет довольно неравномерное химическое строение полимерной матрицы [1]: во-первых, макромолекулы галактоманнана, представляющего макромолекулы поли$(1 \rightarrow 4$-D-маннопиранозы), связанной с регулярно распределенными боковыми привесками $\alpha$-D-галактозы (или $1 \rightarrow 6-\alpha$-D-галактопиранозы), которые, в свою очередь, связаны с включениями манноз и других моносахаридов, - характеризуются высокой композиционной неоднородностью по составу, и во-вторых, сложная комплексная структура ГМ характеризуется широким молекулярно-массовым распределением.

Водорастворимый полисахарид - галактоманнан Gleditsia Aquatica выделяли способом [1], выход составлял $20 \%$. Процесс гидролиза проводили в водных растворах в присутствии $\mathrm{HCl}$. Образцы гидролизовали 40 мин при: 1) $60{ }^{\circ} \mathrm{C}$; 2) $70{ }^{\circ} \mathrm{C}$; 3) $80^{\circ} \mathrm{C}$. Гидролизаты центрифугировали, центрифугаты осаждали в этиловом спирте $(1: 2)$. Выпавшие осадки отделяли, промывали до нейтральной среды спиртом, сушили. Выходы гидролизованных галактоманнанов составили: 1) 88,6\%; 2) 83,16\%; 3) 72,3\% соответственно.

Конформационное строение макромолекул гидролизованных ГМ в растворах будет определяться совокупностью стерических факторов, определяемых строением гидролизованной полимерной матрицы поли-(1 $\rightarrow 4$-D-маннопиранозы) и заданным в процессе гидролиза распределением боковых привесков $\alpha$-D-галактозы (или $1 \rightarrow 6-\alpha$-D-галактопиранозы), а также их молекулярной массой.

Как известно, негидролизованный ГМ растворяется в водных системах и в определенных условиях образует высоковязкие гели, что свидетельствует о высокой ассоциативной способности макромолекул данного полисахарида. Молекулярная масса исследуемого исходного негидролизованного ГМ достаточно высока (табл. 1), в процессе гидролиза с увеличением температуры величины молекулярных масс закономерно снижаются. 
Рис. 1. Структурная формула

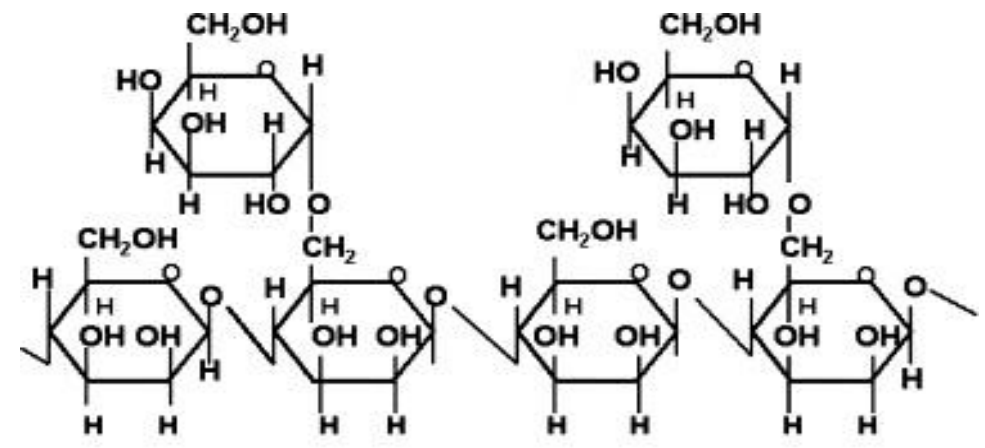

галактоманнана

Таблица 1. Сравнительные характеристики исходного и гидролизованного галактоманнана

\begin{tabular}{c|c|c|c|c}
\hline \multirow{2}{*}{ Основные параметры } & \multicolumn{4}{|c}{ G.aquatica } \\
\cline { 2 - 5 } & исходный ГМ & \multicolumn{3}{|c}{ гидролизованные ГМ } \\
\hline Температура гидролиза & - & $60{ }^{\circ} \mathrm{C}$ & $70{ }^{\circ} \mathrm{C}$ & $80^{\circ} \mathrm{C}$ \\
Соотношение Gal:Man & $1: 1,86$ & $1: 2,11$ & $1: 2,38$ & $1: 2,73$ \\
$\mathrm{M}_{\mathrm{w}}$ & $5,63 \times 10^{5}$ & $2,20 \times 10^{5}$ & $0,28 \times 10^{5}$ & $0,10 \times 10^{5}$ \\
[ๆ], г/дл & 6,15 & 3,00 & 0,71 & 0,33 \\
\hline
\end{tabular}

Под влиянием кислоты в процессе гидролиза идет расщепление макромолекулярной матрицы галактоманнана - тем большее, чем выше температурные условия процесса. Как показывают результаты эксперимента (табл. 1), повышение температуры процесса на $10^{\circ} \mathrm{C}$ приводит к снижению молекулярных масс почти в 10 раз, а на $20{ }^{\circ} \mathrm{C}$ - более чем в 20 раз.

Реологические свойства растворов гидролизованного галактоманнана

Сложная структура высокомолекулярной матрицы ГМ и его гидролизованных производных определяет сложную структуру их концентрированных растворов и комплекс их структурно-механических, реологических свойств. Исследовались реологические свойства концентрированных $3 \%$ водных растворов исходного и гидролизованных образцов ГМ при варьировании температур от 25 до $70{ }^{\circ} \mathrm{C}$.

Для описания течения концентрированных растворов полимеров обычно используются характеристики, получаемые в условиях сдвигового течения: определение зависимости скорости деформации от напряжения сдвига $\lg \mathrm{D}=\mathrm{f}(\lg \tau)$ и числовых значений ее параметров, где $\tau-$ напряжение сдвига, т.е. сила, действующая касательно к ламинарно перемещающимся слоям, отнесенная к единице площади, D - градиент скорости (скорость деформации сдвига), характеризующий изменение скорости на единицу расстояния, измеряемой под прямым углом к направлению скорости $\left(\mathrm{c}^{-1}\right)$, или определение зависимости $\lg \eta=\mathrm{f}(\lg \tau)$ эффективной вязкости $\eta$ от напряжения сдвига $\tau[12,15]$.

Графически указанная функция выражается кривой течения. Зависимость кривых течения водных растворов в зависимости от температур приведена на рисунках 2-5 в логарифмических координатах.

Кривые, приведенные на этих рисунках, характеризуют неньютоновское течение и имеют характер аномалии вязкого течения, свойственный псевдопластикам [11, 12].

Для исследованных систем исходного ГМ на данных кривых течения не удалось зафиксировать участок «наибольшей ньютоновской вязкости», а следовательно, уже при малых скоростях сдвига происходят структурные изменения и изменения вязкости. Для систем растворов гидролизованных ГМ можно зафиксировать участок «наибольшей ньютоновской вязкости», что определяется также степенью гидролиза образцов ГМ.

Как показали экспериментальные данные (рис. 5), увеличение степени гидролиза образцов ГМ приводит к соответственному заметному снижению вязкостных параметров, величин эффективных вязкостей, критических напряжений сдвига, тем большему, чем выше степень гидролиза.

Для исследованных систем растворов ГМ основной причиной аномалии вязкого течения является прогрессирующий распад структуры ассоциированных надмолекулярных образований в растворах гидролизованных природных полисахаридов по мере роста напряжений сдвига. Специфика концентрированных растворов исследованных ГМ, как уже отмечалось, заключается в том, что отдельные макромолекулы не могут перемещаться независимо друг от друга. В таких растворах образуется сложная пространственная система взаимодействующих макромолекул и статистических надмолекулярных образований, которая и обусловливает их эффективную вязкость. На кривых течения растворов ГМ видно наличие только «структурной» ветви, обусловленной механическим разрушением ассоциативной структуры растворов. 


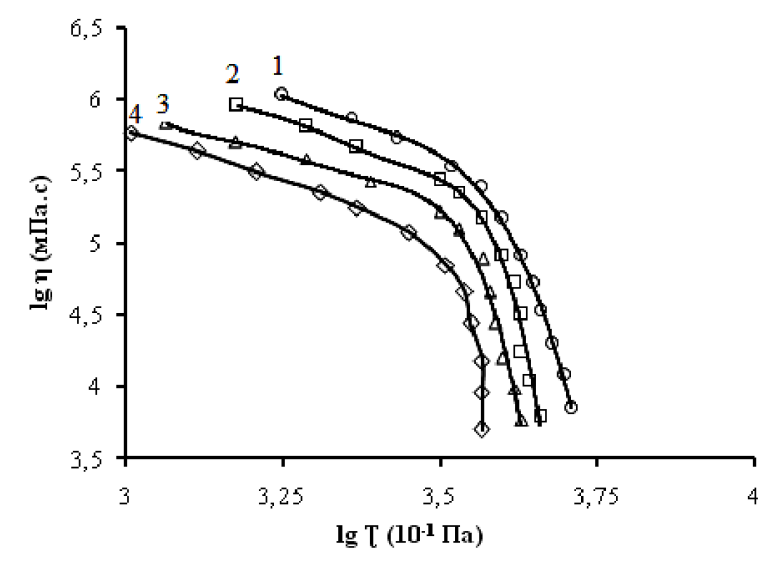

Рис. 2. Кривые течения $3 \%$ водного раствора исходного ГМ с $[\eta]=6,15 ; \mathrm{M}_{\mathrm{w}}=5,63 \times 10^{5}$ при различных температурах: $1-25^{\circ} \mathrm{C} ; 2-40{ }^{\circ} \mathrm{C}$; $3-55^{\circ} \mathrm{C} ; 4-70{ }^{\circ} \mathrm{C}$

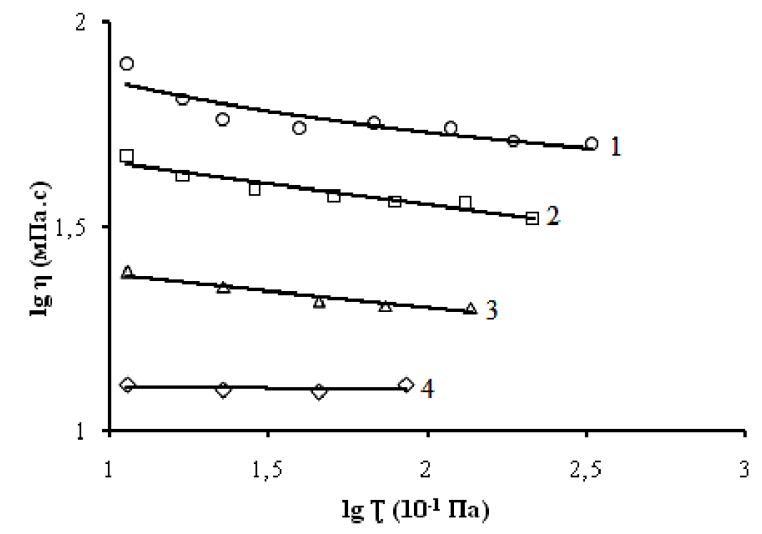

Рис. 4. Кривые течения $3 \%$ водного раствора гидролизованного ГМс [ๆ] $=0,71$ и $\mathrm{M}_{\mathrm{w}}=0,28 \times 10^{5}$ при различных температурах: $1-25{ }^{\circ} \mathrm{C} ; 2-40{ }^{\circ} \mathrm{C}$; $3-55^{\circ} \mathrm{C} ; 4-70{ }^{\circ} \mathrm{C}$

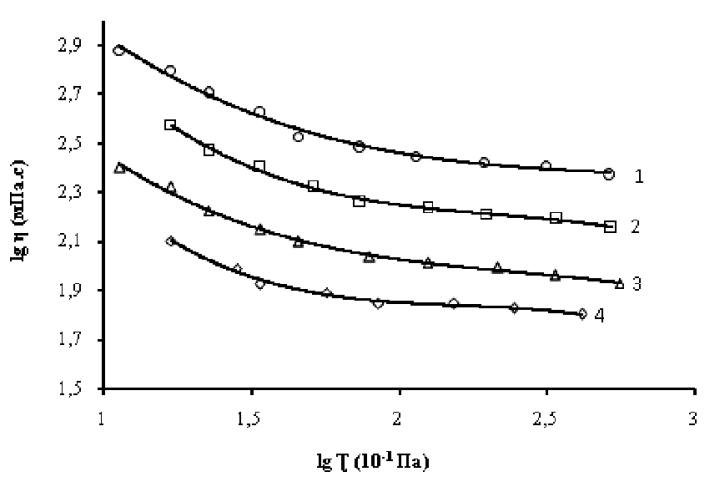

Рис. 3. Кривые течения 3\% водного раствора гидролизованного ГМ с $[\eta]=3$ и $\mathrm{M}_{\mathrm{w}}=2,20 \times 10^{5}$ при различных температурах: $1-25^{\circ} \mathrm{C} ; 2-40{ }^{\circ} \mathrm{C}$; $3-55^{\circ} \mathrm{C} ; 4-70{ }^{\circ} \mathrm{C}$

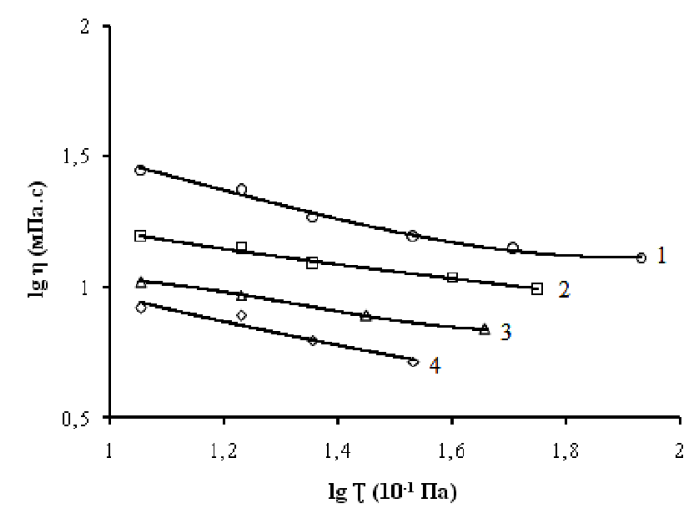

Рис. 5. Кривые течения 3\% водного раствора гидролизованного ГМ с $[\eta]=0,33$ и $\mathrm{M}_{\mathrm{w}}=0,1 \times 10^{5}$ при различных температурах: $1-25{ }^{\circ} \mathrm{C} ; 2-40{ }^{\circ} \mathrm{C}$; $3-55^{\circ} \mathrm{C} ; 4-70{ }^{\circ} \mathrm{C}$

Аномальное изменение эффективной вязкости, характер ее уменьшения в зависимости от роста напряжения сдвига для изученных систем определяется молекулярной массой и соотношением галактозы и маннозы в макромолекуле. Как видно из рисунков 2-5, наиболее высокой аномалией вязкого течения характеризуются эквиконцентрированные системы исходного ГМ с наиболее высокими величинами $\mathrm{M}_{\mathrm{w}}$ и соотношением галактозы и маннозы (табл. 1). Структурная особенность такой полимерной матрицы галактоманнана определяется спецификой строения матричных маннопиранозных и боковых галактопиранозных циклов и высокой ассоциативной способностью формирующихся внутри- и межмолекулярных образований. Для гидролизованных образцов ГМ аномалия вязкого течения выражена более слабо, для этих систем характерны меньшие величины эффективных вязкостей вследствие снижения молекулярных масс макромолекул, снижения количества боковых галактопиранозных циклов, увеличения кинетической подвижности и снижения интенсивности межмолекулярного взаимодействия. Контактные межмолекулярные взаимодействия для этих систем, определяемые в большей степени водородными связями между соседними макромолекулами, существенно слабее за счет изменения структуры макромолекул ГМ в процессе гидролиза, этим объясняется наименее выраженная аномалия вязкого течения и более низкая прочность структуры концентрированных растворов гидролизованных образцов по сравнению с исходным ГМ.

В целом реологические исследования систем водных растворов ГМ и его гидролизованных производных показывают существенные различия в поведении их концентрированных растворов, определяемых структурой исходной матрицы ГМ и степенью гидролиза макромолекул ГМ, величинами молекулярных масс, снижением количества боковых галактопиранозных циклов, а также соотношением галактозы и маннозы. 
Как видно, для исследованных систем повышение температуры приводит к закономерному снижению вязкостных параметров и смещению критических напряжений сдвига в область меньших величин.

Согласно активационной теории, при повышении температуры, когда возможен переход макромолекул из одного равновесного состояния в другое, важную роль играет энергия активации. Исходя из этой теории, Френкель $[11,12,15]$ и Эйринг нашли температурную зависимость ньютоновской вязкости:

$$
\eta=A e^{\Delta E / R T}
$$

где $\Delta \mathrm{E}$ - энергия активации вязкого течения; $\mathrm{R}$ - универсальная газовая постоянная; $\mathrm{T}$ - абсолютная температура; А - константа.

Физический смысл этого уравнения заключается в том, что перемещение молекул или сегментов макромолекул осуществляется путем перескоков из одного состояния равновесия в другое, причем для этого необходимо преодолеть потенциальный барьер вращения, величина которого определяется энергией

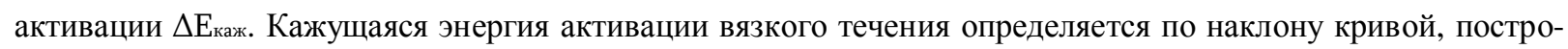
енной в координатах «lg $\eta$ - 1/Т», что следует из уравнения:

$$
\lg \eta=\lg \mathrm{A}+\Delta \mathrm{E}_{\text {каж }} / 2,303 \mathrm{RT} .
$$

Для изученных систем растворов ГМ с различными степенями гидролиза рассчитаны энергии активации вязкого течения по уравнению (1) в диапазоне температур $25-70{ }^{\circ} \mathrm{C}$. Значения величин кажущейся энергии активации вязкого течения $\Delta \mathrm{E}_{\text {каж }}$ являются мерой интенсивности межмолекулярного взаимодействия макромолекул в растворах, а иначе говоря, косвенной характеристикой прочности структуры полимерных текучих систем в растворах.

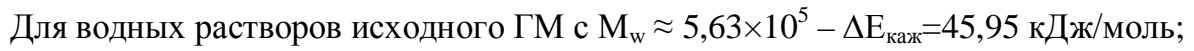
для гидролизованных ГМ:

$$
\begin{aligned}
& \mathrm{M}_{\mathrm{w}} \approx 2,20 \times 10^{5}-\Delta \mathrm{E}_{\text {каж}}=32,54 \text { кДж/моль; } \\
& \mathrm{M}_{\mathrm{w}} \approx 0,28 \times 10^{5}-\Delta \mathrm{E}_{\text {каж }}=29,48 \text { кДж/моль; }
\end{aligned}
$$$$
\mathrm{M}_{\mathrm{w}} \approx 0,10 \times 10^{5}-\Delta \mathrm{E}_{\text {каж}}=30,63 \text { кДж/моль. }
$$

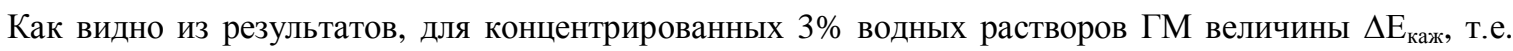
прочности структуры раствора, определяются степенью гидролиза. Концентрированные водные растворы

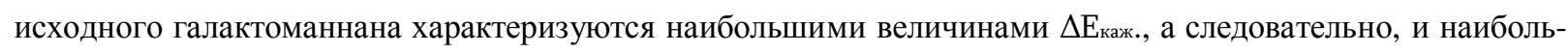
шей прочностью структуры раствора. Изменение структуры ГМ в процессе гидролиза приводит к значительному снижению структурирования системы по сравнению с системой исходного ГМ.

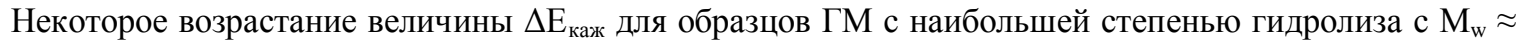
$0,10 \times 10^{5}$ по сравнению с образцом с $\mathrm{M}_{\mathrm{w}} \approx 0,28 \times 10^{5}$ может быть объяснено формированием относительно более прочных ассоциатов вследствие повышения пространственной подвижности полимерной матрицы с низкой молекулярной массой и более низким содержанием количества боковых галактопиранозных циклов, что облегчает формирование водородных связей между соседними макромолекулами и ассоциатами, а также обеспечивает более плотную упаковку макромолекул в агрегатах.

Сопоставляя изменение вязкости и теплоты активации вязкого течения изучаемых систем, можно сделать вывод, что характер изменения этих величин различен. Если величины эффективных вязкостей систем различных образцов гидролизованного галактоманнана несопоставимы и изменяются в различных

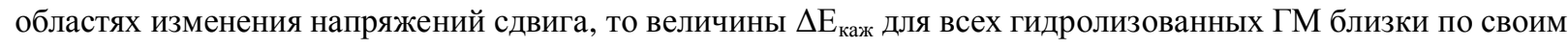
значениям. Это явление, видимо, можно объяснить исходя из гипотезы существования в растворах полимеров двух типов структурных образований, составляющих флуктуационную сетку зацеплений: более прочных и менее прочных, образованных прочными структурами.

Энергия активации вязкого течения, как показано в работах $[11,12,15,16]$, определяется величиной межмолекулярного взаимодействия и прочностью структурных образований в растворах. Вклад в величину этого параметра имеют как образование «прочных» участков структуры в ассоциатах раствора, так и частота контактных взаимодействий в ассоциатах, сформировавшихся посредством водородных связей, а также флуктуационной сетки межассоциативных зацеплений в условиях вязкого течения. В силу этого образование более «прочных» участков структуры в растворе должно оказывать большее влияние на рост энергии активации по сравнению с образованием флуктуационной сетки. Как известно, для растворов полимеров природных полисахаридов (каким является ГМ) «кинетической единицей», перемещающейся при течении, являются не цепь, не сегмент, а агрегаты и ассоциаты, размер которых зависит от природы полиме- 
ра, растворителя, концентрации и температуры. Укладка макромолекул в ассоциаты и их контакты друг с другом зависят от химического строения цепей и соотношения разнородных макромолекул полимерной матрицы ГМ (различных поли- и моносахаридов) в этих ассоциатах, что также определяется природой полимерных матриц полисахаридов.

Изучение структуры концентрированных растворов гидролизованных образцов ГМ с различными молекулярными массами и молекулярным строением интересно в аспекте оценки размеров ассоциативных образований систем ГМ, определяемых структурой гидролизованных макромолекул. Были оценены величины «вязкостных объемов» $\mathrm{V}^{*}$, или среднестатистических размеров кинетических единиц [17]. Величины $\mathrm{V}^{*}$ являются качественной характеристикой, которая позволяет оценить подвижность структурных элементов и их размеры. $\mathrm{V} *$ рассчитывали по формуле:

$$
V^{*}=\frac{2 K[E / R-(\ln \eta-\ln A \cdot \tau) \cdot T]}{\tau},
$$

где К - константа Больцмана; $\mathrm{R}$ - универсальная газовая постоянная; $\tau$ - напряжение сдвига; Т - абсолютная температура, К; А - предэкспоненциальный множитель, имеющий смысл вязкости при бесконечно высокой температуре; Е - кажущаяся энергия активации вязкого течения, определяемая из тангенса угла наклона зависимости $\lg \eta=\mathrm{f}(1 / \mathrm{T})$. Величиной А $\tau$ пренебрегают из-за очень маленького значения.

Величины $\mathrm{V}^{*}$ для растворов образцов ГМ приведены в таблице 2.

Как видно из таблицы, с увеличением температуры во всем диапазоне 298-343 К происходит увеличение величин $\mathrm{V}^{*}$ для всех исследуемых образцов ГМ. Это объясняется тем, что с ростом температуры облегчается процесс разворачивания макромолекул, а также облегчаются межмолекулярные взаимодействия, в результате которых образуются и перегруппировываются ассоциаты различного типа. При увеличении напряжений сдвига происходит постепенное механическое разрушение структурных надмолекулярных ассоциатов, тем больше, чем выше величины напряжений сдвига. Такое разрушение приводит к соответствующему уменьшению размеров ассоциатов вплоть до нановеличин (100 нм) поперечных размеров d для исходного галактоманнана.

Таблица 2. Изменение вязкостного объема $\mathrm{V}^{*}$ от температуры и напряжения сдвига $\tau$ для систем водных растворов образцов ГМ с различной молекулярной массой*

\begin{tabular}{|c|c|c|c|c|c|c|c|c|c|}
\hline \multirow[t]{2}{*}{$\tau$, Па } & \multirow[t]{2}{*}{$\mathrm{T}, \mathrm{K}$} & \multicolumn{2}{|c|}{1} & \multicolumn{2}{|c|}{2} & \multicolumn{2}{|c|}{3} & \multicolumn{2}{|c|}{$\begin{array}{c}4 \\
\text { Исходный ГМ }\end{array}$} \\
\hline & & $\mathrm{V} \times 10^{23}, \mathrm{~m}^{3}$ & $\mathrm{~d} \cdot 10^{9}, \mathrm{M}$ & $\mathrm{V} \times 10^{23}, \mathrm{M}^{3}$ & $\mathrm{~d} \cdot 10^{9}, \mathrm{M}$ & $\mathrm{V} \times 10^{23}, \mathrm{~m}^{3}$ & $\mathrm{~d} \cdot 10^{9}, \mathrm{M}$ & $\mathrm{V} \times 10^{23}, \mathrm{M}^{3}$ & $\mathrm{~d} \cdot 10^{9}, \mathrm{M}$ \\
\hline \multirow{4}{*}{1,585} & 298 & 8366,9 & 437,4 & 7564,0 & 422,9 & 7033,5 & 412,8 & - & - \\
\hline & 313 & 8741,3 & 443,8 & 7910,1 & 429,3 & 7295,5 & 417,8 & - & - \\
\hline & 328 & 9155,3 & 450,7 & 8348,4 & 437,1 & 7713,1 & 425,7 & - & - \\
\hline & 343 & 9473,1 & 455,8 & 8791,8 & 444,7 & 8029,3 & 431,4 & - & - \\
\hline \multirow{4}{*}{10,0} & 298 & 1373,5 & 239,5 & 1221,6 & 230,3 & 1184,9 & 228,0 & - & - \\
\hline & 313 & 1435,3 & 243,0 & 1267,7 & 233,2 & 1230,0 & 230,8 & - & - \\
\hline & 328 & 1476,1 & 245,3 & 1333,7 & 237,1 & 1285,1 & 234,2 & - & - \\
\hline & 343 & 1518,9 & 247,7 & 1393,5 & 240,6 & 1329,4 & 236,9 & - & - \\
\hline \multirow{4}{*}{25,12} & 298 & - & - & 487,8 & 169,6 & 475,5 & 168,2 & - & - \\
\hline & 313 & - & - & 507,0 & 171,8 & 493,6 & 170,3 & - & - \\
\hline & 328 & - & - & 530,9 & 174,5 & 513,3 & 172,5 & - & - \\
\hline & 343 & - & - & 554,7 & 177,0 & 522,7 & 174,6 & - & - \\
\hline \multirow{4}{*}{125,9} & 298 & - & - & - & - & - & - & 72,3 & 89,8 \\
\hline & 313 & - & - & - & - & - & - & 73,0 & 90,0 \\
\hline & 328 & - & - & - & - & - & - & 74,8 & 90,8 \\
\hline & 343 & - & - & - & - & - & - & 75,7 & 91,1 \\
\hline \multirow{4}{*}{251,2} & 298 & - & - & - & - & - & - & 39,6 & 73,5 \\
\hline & 313 & - & - & - & - & - & - & 40,2 & 73,8 \\
\hline & 328 & - & - & - & - & - & - & 41,0 & 74,2 \\
\hline & 343 & - & - & - & - & - & - & 42,3 & 75,0 \\
\hline \multirow{4}{*}{363,1} & 298 & - & - & - & - & - & - & 29,9 & 66,9 \\
\hline & 313 & - & - & - & - & - & - & 30,5 & 67,3 \\
\hline & 328 & - & - & - & - & - & - & 30,8 & 67,6 \\
\hline & 343 & - & - & - & - & - & - & 32,1 & 68,5 \\
\hline
\end{tabular}

*1) $\left.\left.\left.\mathrm{M}_{\mathrm{w}} \approx 0,10 \times 10^{5} ; 2\right) \mathrm{M}_{\mathrm{w}} \approx 0,28 \times 10^{5} ; 3\right) \mathrm{M}_{\mathrm{w}} \approx 2,20 \times 10^{5} ; 4\right) \mathrm{M}_{\mathrm{w}} \approx 5,63 \times 10^{5}$. 
Как уже отмечалось выше, в концентрированных водных растворах образцы ГМ характеризуются высокими интенсивными межмолекулярными взаимодействиями, обусловленными водородными связями, вследствие которых формируются малоподвижные и относительно большие по величине структурные элементы $\left(\mathrm{V}^{*}\right)$. В водных растворах гидролизованного ГМ размеры таких ассоциатов определяются величинами молекулярных масс и молекулярного строения, тенденция изменения размеров ассоциатов в зависимости от строения гидролизованного ГМ аналогична изменению прочностных параметров. Для исходного ГМ при формировании межмолекулярных связей в большей степени пространственно более доступны боковые D-галактопиранозные и, возможно, в меньшей степени менее доступны - матричные линейные маннопиранозные циклы, т.о. макромолекулы способны ассоциировать наиболее близко расположенные функциональные группы. Надо полагать, что при образовании таких ассоциатов идет формирование «более прочных» ассоциатов, имеющих более ближний порядок формирования водородных связей, по сравнению с гидролизованными ГМ. Для исходного ГМ пространственные затруднения будут сказываться на процессах формирования более прочных межмолекулярных ассоциатов, что также отражается на размерах и подвижности структурных элементов. Для гидролизованных образцом ГМ важную роль играет уменьшение молекулярных масс и снижение количества боковых галактопиранозных циклов, изменение соотношений галактозы и маннозы, т.е. пространственно диффузионная возможность полимерной матрицы к формированию ассоциатов; поскольку такие макромолекулы более подвижны при взаимном «поиске» и формировании водородных связей между гидроксильными функциональными группами пиранозных циклов. Для гидролизованных ГМ формирование ассоциатов за счет водородных связей будет идти в более высокой степени между гидроксильными группами матричных линейных маннопиранозных циклов и в меньшей - между остаточными боковыми D-галактопиранозными циклами соседних макромолекул (или ассоциатов) за счет их уменьшения и за счет увеличения подвижности макромолекул гидролизованных ГМ из-за снижения молекулярных масс. Это приводит к формированию более крупных, но менее прочных ассоциатов гидролизованных ГМ. Это также объясняет тот факт, что с увеличением степени гидролиза размеры ассоциатов соответственно увеличиваются.

\section{Bblводbl}

Исследован процесс гидролиза природного полисахарида галактоманнана Gleditsia Aquatica и изучены реологические свойства концентрированных водных растворов гидролизованных образцов ГМ.

1. Изучен процесс гидролиза галактоманнана Gleditsia Aquatica при варьировании температуры и постоянном времени. Процесс гидролиза приводит к изменению молекулярной структуры макромолекулы галактоманнана Gleditsia Aquatica. Установлено, что с повышением температуры процесса степень гидролиза повышается, соответственно закономерно снижаются молекулярные массы образцов ГМ и соотношения галактозы и маннозы.

2. Изучены процессы вязкого течения водных растворов гидролизованных производных галактоманнана. Показано, что все изученные системы являются неньютоновскими жидкостями с псевдопластичным типом аномалии вязкого течения, который определяется структурой и молекулярными массами образцов.

3. Исследовано влияние температуры на процессы вязкого течения концентрированных систем ГМ.

Рассчитаны величины кажущихся энергий активации вязкого течения растворов, являющихся косвенной характеристикой прочности структур систем. Показано, что наибольшими величинами энергий активации характеризуются системы исходного негидролизованного ГМ. Показано, что величины энергий активации вязкого течения растворов ГМ определяются степенью гидролиза образцов.

4. Оценена структура водных растворов систем ГМ по величинам среднестатистических размеров кинетических единиц, позволяющим сравнить подвижность структурных элементов и их размеры для концентрированных систем.

Показано, что степень гидролиза ГМ и молекулярное строение является основным фактором, определяющим структуру концентрированных растворов на их основе.

\section{Список литературы}

1. Рахманбердыева Р.К. Полисахариды растений рода Gleditsia и Cardaria repens: дис. ... д-ра хим. наук. Ташкент, 2011. 
2. Gimenez-Abian M., Bernabe M., Leal J.A., Jimenez-Berbero J., Prieto A. Structure of a galactomannan isolated from the cell wall of the fungus Lineolata rhizophorae // Carbohyd. Res. 2007. N10(342). Pp. 2599-2603.

3. Анулов О.В., Смирнова Н.И., Местичкина Н.М. Характеристика и структура галактоманнана Астрагала серпоплотного (Astragalus falcatus Lam.) // Прикладная биохимия и микробиология. 1995. №6(31). С. 645-649.

4. Щербухин В.Д. Глактоманнаны отечественной флоры // Прикладная биохимия и микробиология. 1993. №6(29). С. 803-813.

5. Голубев В.Н., Ничева-Филатова Л.В., Шеленская Т.В. Пищевые и биологически активные добавки. М., 2003. C. $71-80$.

6. Christine J.G. Duncan, Pugh N., Pasko D.S., Ross S.A. Isolation of a galactomannan that macrobhage activation edible fungus Morchella esculenta // J. Agric. Food Chem. 2002. N50(20). Pp. 5683-5685.

7. Местечкина Н.М., Щербухин В.Д., Банникова Г.Е., Варламов В.П., Дрозд Н.Н., Толстенков А.С., Макаров В.А., Тихинов В.Е. Антикоагулянтная активность низкомолекулярных сульфатированных производных галактоманнана семян Cyamopsis tetragonoloba (L.) Taub. // Прикладная биохимия и микробиология. 2008. №1(44). C. 111-11

8. Gamal-Eldeen Amira M., Amer H., Helmy W.A., Ragab H.M., Talaat Roba M. Antiproliferative and canserchemopreventive properties of sulfated glycosylated extract derived from Leucaena leucocephala // Indian J. of Pharm. 2007. N6(69). Pp. 805-811.

9. Boban Puthenpura T., Nambisan Bala, Sudhararan Perumanan. Hypolipidaemic effect of chemically different mucilages in rats // British J. of Nutrition. 2006. N6(96). Pp. 1021-1029.

10. Мансветова Е.М. Пищевые полисахариды и их использование в мясной промышленности // Мясная индустрия. 2008. №12. С. 25-29.

11. Папков С. П. Физико-химические основы переработки растворов полимеров. М., 1971. 372 с.

12. Виноградов Г.В., Малкин А.Я. Реология полимеров. М., 1977. 44 с.

13. Степаненко Б.Н. Химия и биохимия углеводов (полисахариды). М., 1978. 52 с.

14. Боймирзаев А. Определение молекулярно-массовых параметров производных целлюлозы методом эксклюзионной хроматографии // Журнал физической химии. 2006. Т. 80. №8. 1527 с.

15. Торнер Р.В. Теоретические основы переработки полимеров. М., 1977. 464 с.

16. Теплофизические и реологические характеристики полимеров / под общ. ред. Ю.С.Липатова. Киев, 1977. 244 с.

17. Калантарова Т.Д. Термодинамические характеристики и структурные особенности смесей полимеров на основе поливинилпирролидона и метилцеллюлозы : дис. ... канд. хим. наук. Ташкент. 1977.

Поступило в редакиию 11 ноября 2013 г.

После переработки 18 июня 2014 г. 
Amonova D.M. , Mukhamedzhanova M.Yu., Shomurotov Sh.A., Turayev A.S. RHEOLOGICAL PROPERTIES OF THE CONCENTRATED AQUEOUS SOLUTIONS OF HYDROLYZED GALACTOMANNAN DERIVATIVES

Institute of Bioorganic chemistry of the Uzbek Academy of Sciences, H.Abdullaeva, 83, Tashkent, 100125 (Uzbekistan), e-mail: dilya87-82@mail.ru

A process of acidic hydrolysis of natural polysaccharide of galactomannanfrom GleditsiaAquatica was studied on temperature changes and time constant. It is shown that the molecular weight of galactomannans, a ratio of galactose and mannose are decreasing with increasing of hydrolysis temperature. The processes of viscous flow of aqueous solutions of hydrolysedgalactomannan derivatives were investigated in different temperatures. It is shown that all of the studied systems were non-Newtonian fluids with pseudo-plastic type of viscous flow aperiodicities.

Structure of aqueous solutions of the hydrolyzed galactomannan samples was estimated by values of average sizes of kinetic units to compare the mobility of the structural components and their sizes for concentrated systems.

It is shown that the molecular structure of galactomannan is the main factor of determining the structure of their concentrated solutions. The size of associates is increased accordingly in increasing of the degree of hydrolysis, forming more larger but less stable associates of hydrolysedgalactomannans.

Keywords: galactomannan, hydrolysis, effective viscosity, rheology, shear stress, activation energy of the viscous flow.

\section{References}

1. Rahmanberdyeva R.K. Polisaharidy rastenij roda Gleditsia i Cardaria repens, Dokt. diss. [Polysaccharides plants of the genus Gleditsia i Cardaria repens, Doctor. diss.]. Tashkent, 2011. (in Russ.)

2. Gimenez-Abian M., Bernabe M., Leal J.A., Jimenez-Berbero J., Prieto A. Carbohyd. Res., 2007, no. 10(342), pp. 2599-2603.

3. Anulov O.V., Smirnova N.I., Mestichkina N.M. Prikladnaja biohimija i mikrobiologija, 1995, no. 6(31), pp. 645649. (in Russ.)

4. Shherbuhin V.D. Prikladnaja biohimija i mikrobiologija, 1993, no. 6(29), pp. 803-813. (in Russ.)

5. Golubev V.N., Nicheva-Filatova L.V., Shelenskaja T.V. Pishhevye i biologicheski aktivnye dobavki. [Food and dietary supplements]. Moscow, 2003, pp. 71-80. (in Russ.)

6. Christine J.G. Duncan, Pugh N., Pasko D.S., Ross S.A. J. Agric. Food Chem, 2002, no. 50(20), pp. 5683-5685.

7. Mestechkina N.M., Shherbuhin V.D., Bannikova G.E., Varlamov V.P., Drozd N.N., Tolstenkov A.S., Makarov V.A., Tihinov V.E. Prikladnaja biohimija i mikrobiologija, 2008, no. 1(44), pp. 111-11. (in Russ.)

8. Gamal-Eldeen Amira M., Amer H., Helmy W.A., Ragab H.M., Talaat Roba M. Indian J. of Pharm, 2007, no. 6(69), pp. 805-811.

9. Boban Puthenpura T., Nambisan Bala, Sudhararan Perumanan. British J. of Nutrition, 2006, no. 6(96), pp. 1021-1029.

10. Mansvetova E.M. Mjasnaja industrija, 2008, no. 12, pp. 25-29. (in Russ.)

11. Golubev V.N., Nicheva-Filatova L.V., Shelenskaja T.V. Pishhevye i biologicheski aktivnye dobavki. [Physicochemical bases of processing of polymer solutions]. Moscow, 2003, pp. 71-80. (in Russ.)

12. Vinogradov G.V., Malkin A.Ja. Reologija polimerov. [Rheology of polymers]. Moscow, 1977, 44 p. (in Russ.)

13. Stepanenko B.N. Himija i biohimija uglevodov (polisaharidy). [Chemistry and biochemistry of carbohydrates (polysaccharides)]. Moscow, 1978, 52 p. (in Russ.)

14. Bojmirzaev A. Zhurnal fizicheskoj himii, 2006, vol. 80, no. 8, 1527 p. (in Russ.)

15. Torner R.V. Teoreticheskie osnovy pererabotki polimerov. [Theoretical foundations of polymer processing]. Moscow, 1977, 464 p. (in Russ.)

16. Teplofizicheskie i reologicheskie harakteristiki polimerov / ed. Ju.S.Lipatova. [Thermal and rheological properties of polymers / ed. Ju.S.Lipatova.] Kiev, 1977, 244 p. (in Russ.)

17. Kalantarova T.D. Termodinamicheskie harakteristiki $i$ strukturnye osobennosti smesej polimerov na osnove polivinilpirrolidona i metilcelljulozy, kand. diss. [Thermodynamic characteristics and structural features of polymer blends based on polyvinylpyrrolidone and methylcellulose, PhD.]. Tashkent. 1977. (in Russ.)

Received November 11, 2013

Revised June 18, 2014

*Corresponding author. 
